\title{
Hypertrophic Osteoarthropathy Presenting as Rheumatoid Arthritis Mimicker: A Case Report
}

\author{
Firdevs Ulutaş ${ }^{1}$, Meral Ulu ${ }^{2}$, Uğur Karasu ${ }^{1}$, Veli Çobankara ${ }^{1}$ \\ 1. Rheumatology, Pamukkale University, Denizli, TUR 2. Internal Medicine, Pamukkale University, Denizli, TUR
}

Corresponding author: Firdevs Ulutaş, firdevsulutas1014@gmail.com

\begin{abstract}
Paraneoplastic rheumatologic syndromes are defined as clinical conditions that mimic primary rheumatic disease in the course of cancer; they generally improve with the effective treatment of underlying malignancy. Hypertrophic osteoarthropathy (HOA) is one of the paraneoplastic syndromes, and it is characterized by the combined presence of periostosis, digital clubbing, and swelling of soft tissues, skin, and joints in the distal extremities. HOA is commonly associated with intrathoracic malignancies (primary lung tumors or metastases). In this report, we discuss a patient with HOA secondary to lung adenocarcinoma, who was admitted with symmetric polyarthritis presenting as elderly onset rheumatoid arthritis. He was successfully treated with chemotherapy ablation for underlying malignancy. Antiinflammatory drugs were also administered. HOA should be kept in mind in the differential diagnosis of inflammatory arthritis.
\end{abstract}

Categories: Internal Medicine, Rheumatology

Keywords: hypertrophic osteoarthropathy, elderly onset rheumatoid arthritis

\section{Introduction}

In elderly patients, the differential diagnosis of inflammatory polyarthritis generally includes many clinical conditions such as polyarticular gout, pseudogout, elderly onset rheumatoid arthritis, osteoarthritis, and paraneoplastic syndromes. Paraneoplastic rheumatologic syndromes are defined as clinical conditions that mimic primary rheumatic disease in the course of cancer; these conditions generally improve with the treatment of underlying malignancy [1]. Hypertrophic osteoarthropathy (HOA) is one of the paraneoplastic syndromes, and it is characterized by the combined presence of periostosis, digital clubbing, and swelling of soft tissues, skin, and joints in the distal extremities. HOA is commonly associated with intrathoracic malignancies (primary lung tumors or metastases), especially with non-small cell lung cancer with poor prognosis [2].

\section{Case Presentation}

Received 06/26/2020

Review began 06/30/2020 Review ended 07/08/2020 Published 07/19/2020

\section{(c) Copyright 2020}

Ulutaş et al. This is an open access article distributed under the terms of the Creative Commons Attribution License CC-BY 4.0., which permits unrestricted use, distribution, and reproduction in any medium, provided the original author and source are credited.
A 61-year-old man presented with a three-month history of worsening diffuse join pain, three hours of morning stiffness, and swelling of both hands, wrists, and knees. He was initially evaluated at the rheumatology outpatient clinic. He showed no pulmonary symptoms including chest pain, hemoptysis, cough, or shortness of breath. He had no systemic symptoms such as fever and weight loss. He had been a smoker for 10 years until he quit. On physical examination, subtle digital clubbing, symmetric arthritis of wrists, ankles, and metacarpophalangeal joints were determined. Tenderness on palpation was present on the bilateral tibia shaft. Laboratory results revealed no positive rheumatologic markers including rheumatoid factor, anti-citrullinated protein antibodies (anti-CCP), and anti-nuclear antibodies (ANA). Routine tests were normal except for markedly increased c-reactive protein and erythrocyte sedimentation rate. The conventional radiography images revealed periosteal reaction including proliferation, irregularity, and elevation of periosteum on phalanges and tibia (Figures 1,2), and showed a well-defined nodular mass in the right upper lung lobe (Figure 3). The patient underwent fluorodeoxyglucose-positron emission tomography imaging (FDG-PET) and transbronchial biopsy, respectively. PET showed increased uptake of FDG in the nodular lesion (Figure 4). Ultimately, histopathological findings including tumor cells with peripheral nuclear polarization suggested the diagnosis of lung adenocarcinoma (Figure 5). He was treated with palliative chemotherapy. Analgesics and non-steroidal anti-inflammatory drugs (NSAIDs) were used to relieve joint pain. After the second month of treatment, the daily consumption of NSAIDs decreased and the patient's condition improved. Acute phase reactants returned to normal ranges. 


\section{Cureus}

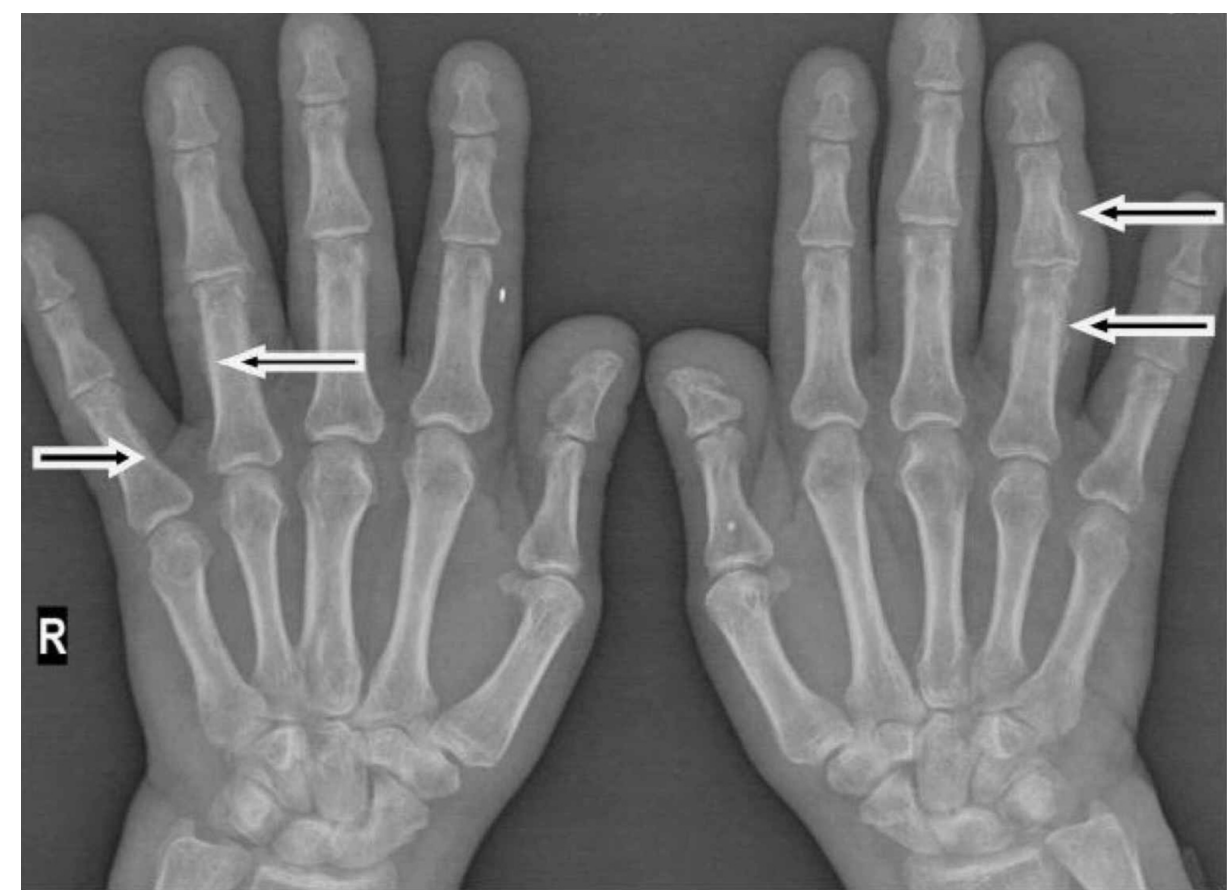

FIGURE 1: Conventional radiography image 1

The image shows periosteal reaction including proliferation, irregularity, and elevation of periosteum on phalanges (arrows)

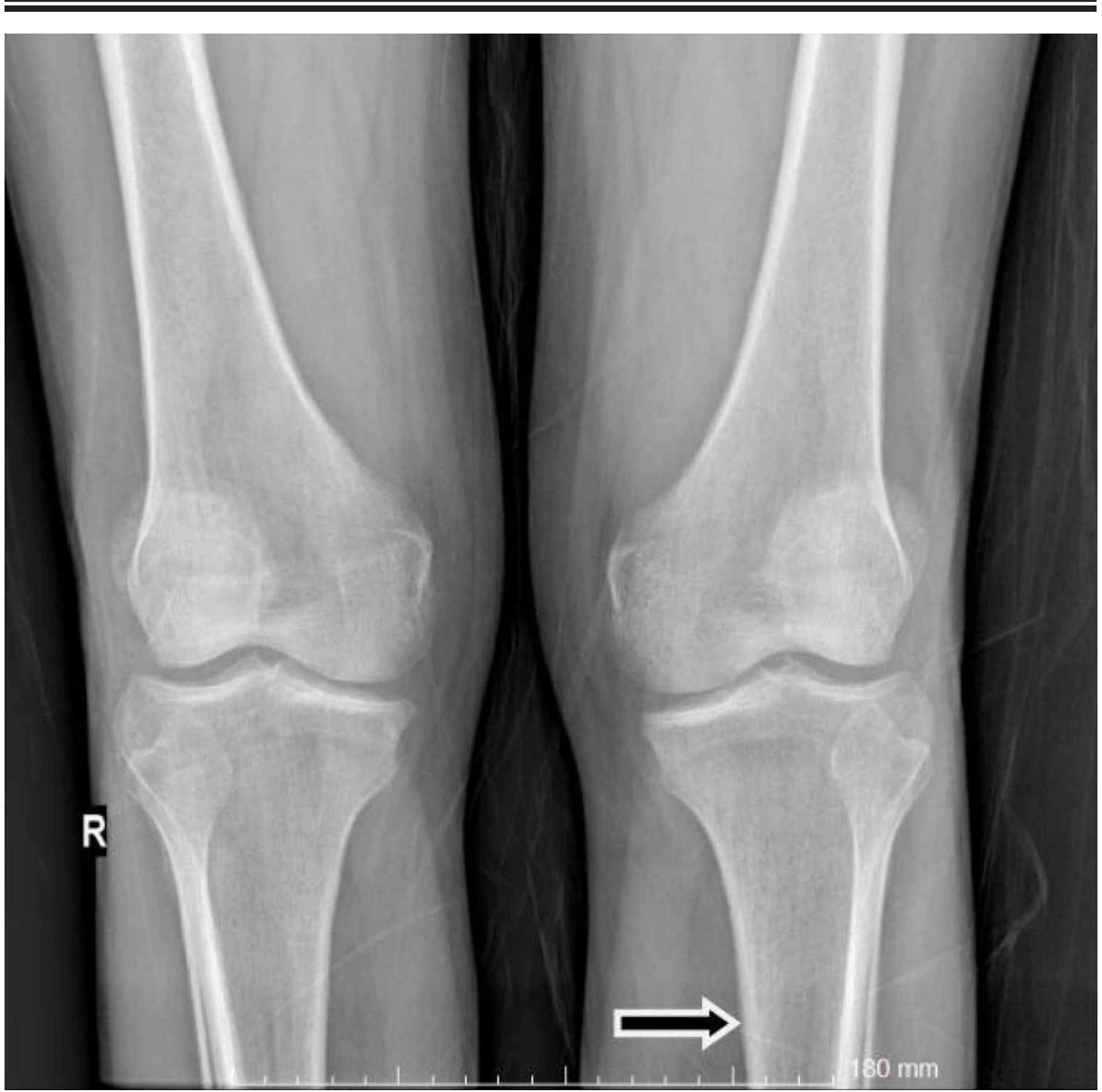

FIGURE 2: Conventional radiography image 2

The image shows periosteal reaction including proliferation, irregularity, and elevation of periosteum on the tibia (arrow) 


\section{Cureus}

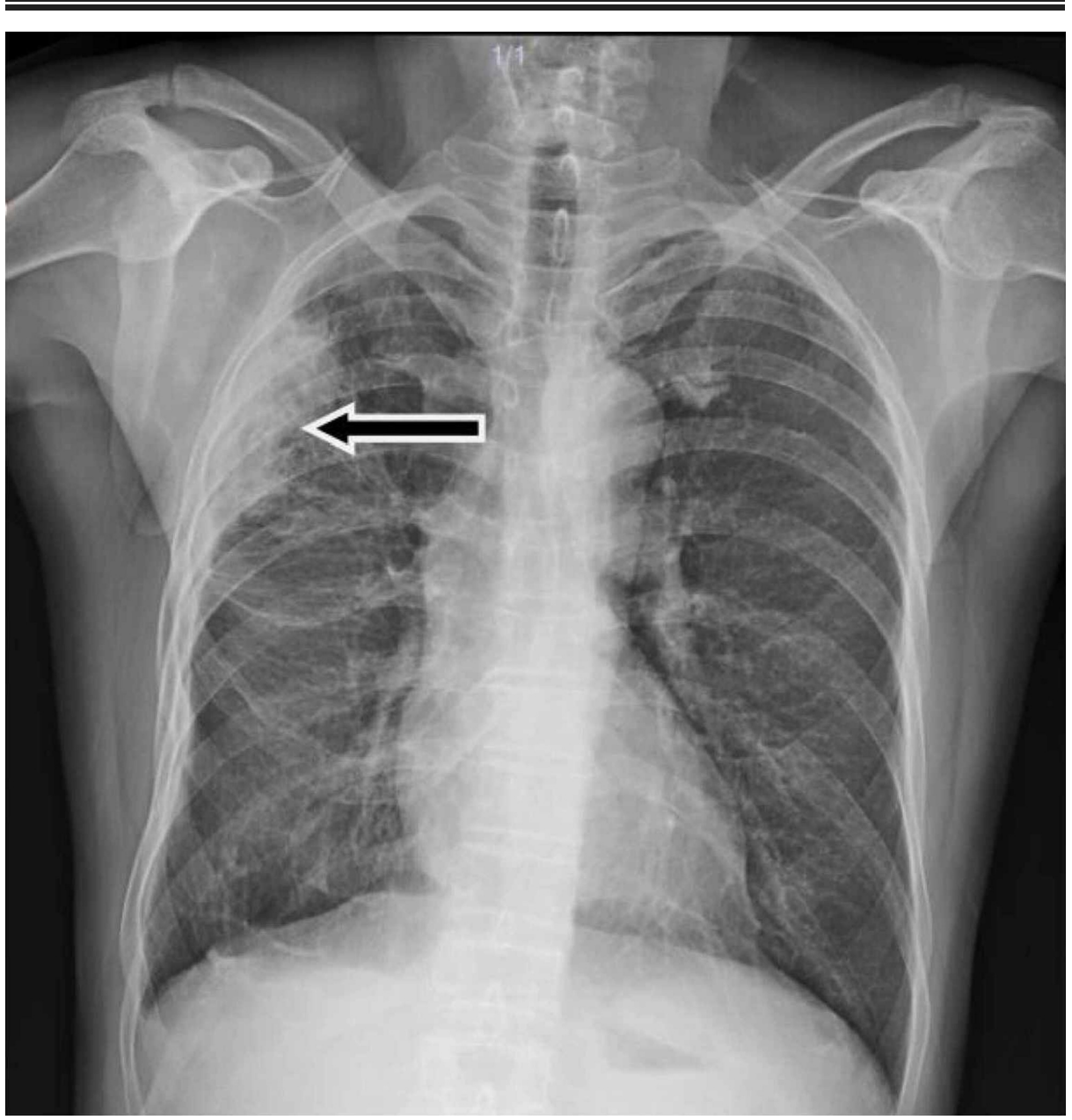

FIGURE 3: Posteroanterior chest radiography

The image shows a well-defined nodular mass in the right upper lung lobe (arrow) 


\section{Cureus}

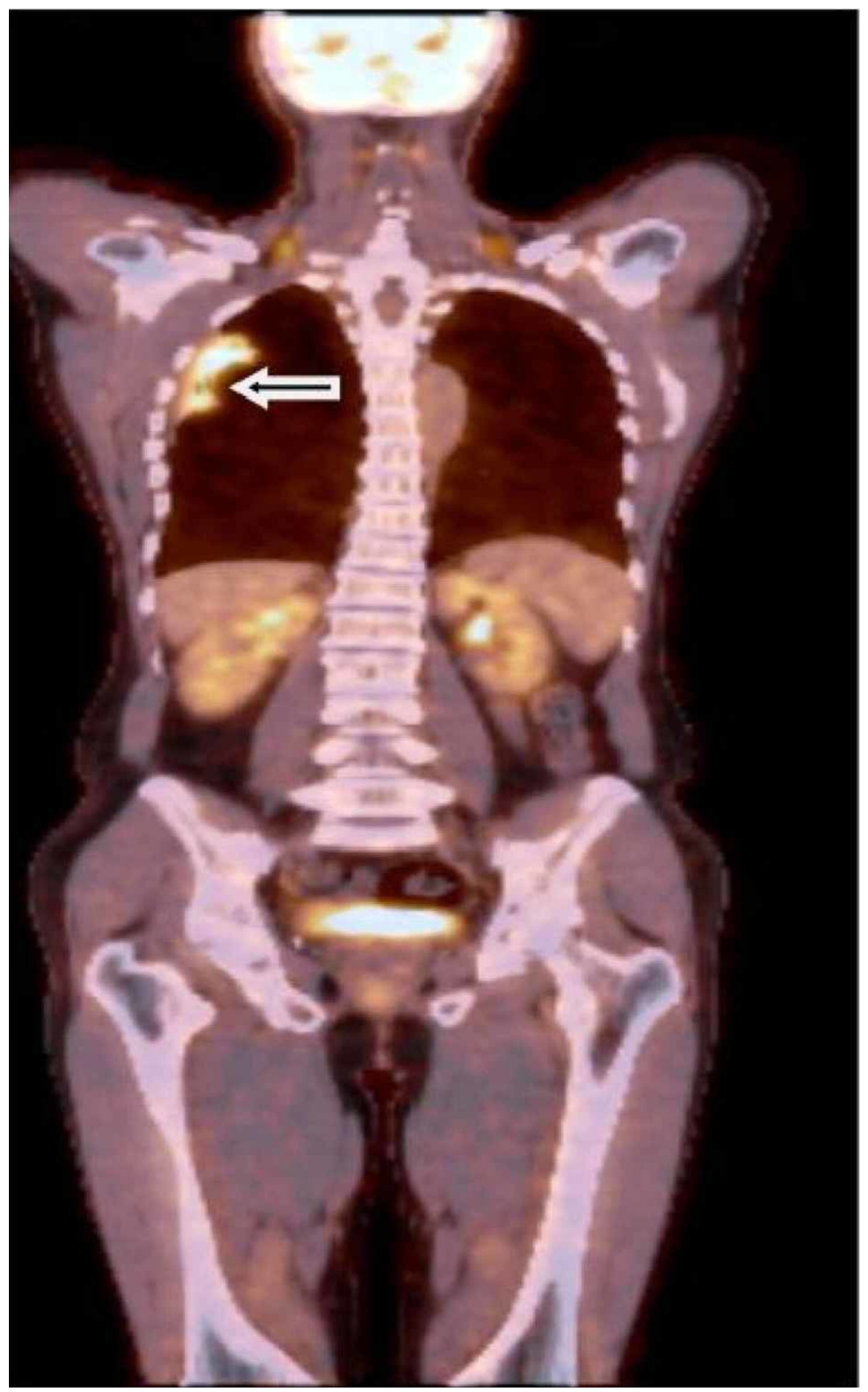

FIGURE 4: Fluorodeoxyglucose-positron emission tomography imaging

The image shows increased uptake of FDG in the nodular lesion (arrow) 


\section{Cureus}

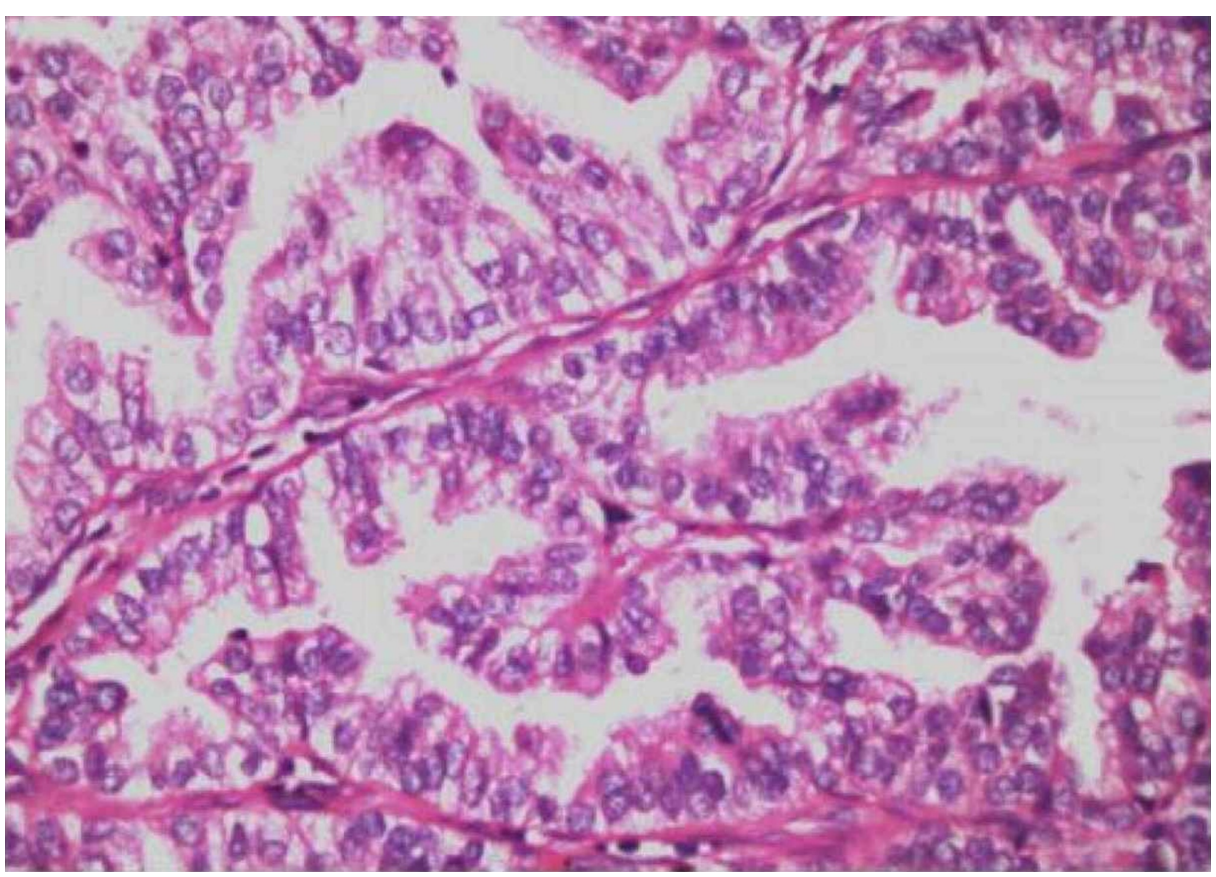

\section{FIGURE 5: Histopathological findings}

The image shows lung adenocarcinoma, a round array of tumor cells with peripheral nuclear polarization (HE *200 Pathology Archive)

\section{Discussion}

HOA is often a paraneoplastic phenomenon as mentioned above [3]. Paraneoplastic rheumatologic syndromes may precede the diagnosis of malignancy such as the one found in our patient or may occur simultaneously. A rapid, atypical onset or progressive course of the disease, or poor response to treatment should raise suspicion among clinicians regarding the paraneoplastic nature of rheumatic diseases [4].

Vascular endothelial growth factor (VEGF), platelet-derived growth factor, and increased levels of prostaglandin E2 are well-known factors in the pathogenesis of the disease [5]. VEGF is the most known factor, and it plays a key role. High serum and plasma concentrations of VEGF in patients with lung cancerrelated HOA have been reported [6]. VEGF is a hypoxia-induced agent that is produced by malignant tumors for the growth of cancer cells. Localized activation of platelets and endothelial cells occurs via the subsequent release of these growth factors. This activation stimulates angiogenesis, endothelial hyperplasia, the proliferation of mesenchymal connective tissue, and the deposit of collagen fibers [7].

Ulusakarya et al. have reported the case of a patient diagnosed with HOA and metastatic lung disease of nasopharyngeal carcinoma. Following the chemotherapy courses, the patient's analgesic consumption decreased and HOA disappeared with complete antitumor response [8]. Management of the condition and survival are dependent on the underlying disease. Its effective treatment may rapidly lead to the resolution of symptoms.

HOA may have variable clinical presentations, mimicking various rheumatic diseases such as rheumatoid arthritis, as found in our case. Bozzao et al. have recently reported a case with HOA and lung adenocarcinoma that presented with initial symptoms including fever, diarrhea, and oligoarthritis [9]. In our case, a worsened digital clubbing prompted us to investigate further. Although clinicians are capable of recognizing advanced cases with clubbing, subtle presentations can be easily missed. Currently, there is no gold standard assay for the detection of clubbing. Increased phalangeal depth ratio or the Schamroth window test may help clinicians before clubbing is markedly developed [10]. For the subtle disease, assuming the presence of clubbing and searching for underlying malignancy may be the best approach for early diagnosis of occult cancer.

\section{Conclusions}

HOA should be kept in mind in the differential diagnosis of inflammatory arthritis. Red flags like digital clubbing and a history of smoking among patients should raise suspicion among clinicians regarding a paraneoplastic condition in the routine clinical practice. 


\section{Additional Information}

Disclosures

Human subjects: Consent was obtained by all participants in this study. Conflicts of interest: In compliance with the ICMJE uniform disclosure form, all authors declare the following: Payment/services info: All authors have declared that no financial support was received from any organization for the submitted work. Financial relationships: All authors have declared that they have no financial relationships at present or within the previous three years with any organizations that might have an interest in the submitted work. Other relationships: All authors have declared that there are no other relationships or activities that could appear to have influenced the submitted work.

\section{References}

1. Schmalzing M: Paraneoplastic syndromes in rheumatology. (Article in German) . Z Rheumatol. 2018, 77:309321. 10.1007/s00393-018-0445-2

2. Yap FY, Skalski MR, Patel DB, et al.: Hypertrophic osteoarthropathy: clinical and imaging features . Radiographics. 2017, 37:157-195. 10.1148/rg.2017160052

3. Vandemergel X, Renneboog B: Prevalence, aetiologies and significance of clubbing in a department of general internal medicine. Eur J Intern Med. 2008, 19:325-329. 10.1016/j.ejim.2007.05.015

4. Parada-Turska J: Paraneoplastic rheumatologic syndromes in the elderly. (Article in Polish) . Wiad Lek. 2019, 72:1646-1654.

5. Nahar I, Al-Shemmeri M, Hussain M: Secondary hypertrophic osteoarthropathy: new insights on pathogenesis and management. Gulf J Oncolog. 2007, 1:71-76.

6. Silveira LH, Martínez-Lavín M, Pineda C, Fonseca MC, Navarro C, Nava A: Vascular endothelial growth factor and hypertrophic osteoarthropathy. Clin Exp Rheumatol. 2000, 18:57-62.

7. Manzini CU, Colaci M, Ferri C, Manzini E: Paraneoplastic rheumatic disorders: a narrative review . Reumatismo. 2018, 70:199-211. 10.4081/reumatismo.2018.1069

8. Ulusakarya A, Gumus Y, Brahmi N, et al.: Symptoms in cancer patients and an unusual tumor: case 1 . Regression of hypertrophic pulmonary osteoarthropathy following chemotherapy for lung metastases of a nasopharyngeal carcinoma. J Clin Oncol. 2005, 23:9422-9423. 10.1200/JCO.2004.00.8474

9. Bozzao F, Bernardi S, Dore F, Zandonà L, Fischetti F: Hypertrophic osteoarthropathy mimicking a reactive arthritis: a case report and review of the literature. BMC Musculoskelet Disord. 2018, 19:145. 10.1186/s12891-018-2068-9

10. Pallarés-Sanmartín A, Leiro-Fernández V, Lourido Cebreiro T, Botana-Rial M, Fernández-Villar A: Validity and reliability of the Schamroth sign for the diagnosis of clubbing. JAMA. 2010, 304:159-161. 10.1001/jama.2010.935 